\title{
LÓGICAS INSTITUCIONAIS POLICIAS MILITARES: ORGANIZAÇÕES HÍBRIDAS E SUAS RELAÇÕES COM O NÍVEL INDIVIDUAL
}

\author{
MILITARY POLICE INSTITUTIONAL LOGICS: HIBRID ORGANIZATITIONS \\ AND THEIR RELATIONS WITH THE INDIVIDUAL LEVEL \\ Felipe Haleyson Ribeiro dos Santos
}

RESUMO: Este artigo busca analisar como as Lógicas Institucionais orientam a construção da identidade profissional policial militar, por meio da realização de um Estudo de Caso na Polícia Militar do Paraná (PMPR). As Lógicas Institucionais podem ser compreendidas por meio de seus elementos práticos, de identidade, objetos e de valor. Para isso foram utilizadas as perspectivas do Identity Work (WATSON, 2008), Práticas sociais (GIDDENS, 2003) e Sensemaking (WEICK, 1995) como apoio para analisar este fenômeno. Para realizar este estudo de caso qualitativo (STAKE, 2009), foram adotadas entrevistas narrativas com indivíduos que compunham a corporação. Por meio das análises que foram realizadas foi possível construir uma narrativa de um indivíduo genérico que continham os elementos coletados nas entrevistas que foram realizadas, e por meio da qual foi possível alcançar o nosso objetivo. A conclusão a que se chegou é que as Lógicas Institucionais orientam a construção da identidade profissional dos sujeitos por uma orientação do Institucional Substance corporificado em práticas, atributos de identidade e objetos, contudo também foi identificado que o Sensemaking pode ser um dos responsáveis por articular os níveis e que as organizações podem atuar como Sensegivers de tal processo, mesmo sendo orientadas pelas Lógicas Institucionais que se encontram imersas.

palaVras-chave: Lógica Institucional; Polícia Militar; Construção da identidade profissional

ABSTRACT: This article analyzes how the Institutional Logics guide the construction of the military police professional identity, through the accomplishment of a Case Study in the Military Police of Paraná (PMPR). Institutional Logics can be understood through its practical elements, identity, objects and value. We used the perspectives of Identity Work (WATSON, 2008), Social Practices (GIDDENS, 2003) and Sensemaking (WEICK, 1995) to support this phenomenon. To carry out this qualitative case study (STAKE, 2009), narrative interviews were conducted with individuals who made up the corporation. Through the analyzes that were carried out it was possible to construct a narrative of a generic individual that contained the elements collected in the interviews that were carried out, and through which it was possible to reach our objective. The conclusion that has been reached is that the Institutional Logics guide the construction of the professional identity of the subjects by an orientation of the Institutional Substance embodied in practices, attributes of identity and objects, however it has also been identified that Sensemaking may be one of the responsible for articulating the levels and that organizations can act as Sensegivers of such process, even if they are guided by the Institutional Logics that are immersed.

Keywords: Institutional Logics; Military Police; Construction of the Professional Identity. 


\section{INTRODUÇÃO}

Compreender a complexidade organizacional demanda adotar alguns conceitos teóricos para facilitar a análise a fim de poder visualizar determinados processos que se estabelecem nos meios organizacional e institucional. Thornton, Ocasio e Lounsbury (2012) afirmam que adotar a perspectiva da Lógica Institucional permite compreender como o nível societal influencia o nível individual e vice-versa. Portanto, ao analisar a interação entre estes níveis, é possível compreender de uma melhor forma as complexidades das organizações que se apresentam, e desafiam os estudos organizacionais.

Quando se trata de uma tentativa de analisar uma organização policial, esta perspectiva também aparenta se encaixar como a mais adequada uma vez que a complexidade do serviço que a Polícia Militar realiza demanda o apoio de uma teoria que apresente outras perspectivas adicionais a fim de permitir compreender o fenômeno em análise com maior precisão.

A Polícia Militar do Paraná (PMPR) apresenta uma estrutura baseada na hierarquia e na disciplina em que os seus indivíduos ocupam posições definidas, nas quais eles realizam o Sensemaking de uma forma constante devido aos gatilhos demandados pelo ambiente (WEICK, 1995). Contudo, esta mesma estrutura demanda que tal processo seja orientado por um superior hierárquico, uma vez que a disciplina demanda obediência às ordens emanadas por ele o que também indica a ocorrência de um processo de Sensegiving (GIOIA; CHITTIPEDDI, 1991). Portanto, o Sensemaking ocorre de forma individualmente livre, mas orientada por uma estrutura hierárquica rígida.

Assim, nessa relação contínua entre Sensemaking/Sensegiving o indivíduo pode ter a sua identidade profissional construída. Tal identidade pode ser observada por meio dos atributos que ela apresenta (LOK, 2010; THORNTON; OCASIO; LOUNSBURY, 2012) Ou então por meio dos papéis que os indivíduos apresentam durante as suas relações sociais. Contudo, independente da perspectiva identitária adotada, algumas organizações podem adotar mecanismos que orientem os indivíduos a adotarem elementos da identidade que a representem, o que no caso deste artigo seria uma identidade policial militar socialmente construída (WATSON, 2008).

Portanto, adotar a perspectiva da Lógica Institucional pode aumentar o espectro da análise e observarmos a organização como um todo. Contudo, dentre os estudos que foram realizados no âmbito das Lógicas Institucionais, existem aqueles que compreendem que algumas organizações apresentam um comportamento híbrido devido à necessidade de se adequaram às conflitantes lógicas que orientam as práticas adotadas por seus indivíduos (BATTILANA; DORADO, 2010), e a Polícia Militar pode ser compreendida como uma organização híbrida devido às tensões que são estabelecidas principalmente pelo seu caráter militar e policial e também devido às diferentes atividades que 
realiza (policiamento montado, policiamento ambiental), assim neste artigo iremos analisar como as lógicas institucionais atuam como orientadoras das práticas adotadas pelos indivíduos, intermediada pelas organizações que eles se encontram imersos. Para tanto, será apresentado a fundamentação teórica que norteia este artigo, para em seguida expormos o caminho metodológico adotado para, em seguida, concluir com os dados e as conclusões encontradas nesta pesquisa.

\section{REFERENCIAL TEÓRICO}

Em 1991, Friedland e Alford publicaram um artigo que apresentaram o conceito de que a sociedade ocidental poderia ser compreendida como composta por Ordens Institucionais distintas, como a família e o mercado por exemplo, e que cada Ordem apresentaria, por consequência, uma Lógica Institucional distinta que orientaria as práticas realizadas pelos indivíduos.

A partir deste pressuposto, os autores indicaram que a cultura passaria a ser algo externo ao indivíduo, uma vez que a Lógica Institucional seria por ela influenciada, o que por sua vez influenciaria as práticas adotadas pelos indivíduos, e a cultura também seria vista como heterogênea, uma vez que ao se considerar que as práticas podem ser influenciadas por diversas Lógicas Institucionais, a cultura seria compartilhada por vários indivíduos, o que a faz perder o caráter homogêneo anteriormente reconhecido nos estudos do Institucionalismo Organizacional (THORNTON; OCASIO, 2008).

Esse conceito sobre a cultura influenciou a perspectiva apresentada por Thornton, Ocasio e Lounsbury (2012), pois conforme pode ser visualizado na figura 01 .

Neste quadro é possível compreender a forma de como a Lógica Institucional emerge a nível de campo. Vale a pena notar que apesar dela advir de um nível societal, para alcançar o nível de campo é necessário que ela passe pelas práticas adotadas pelos indivíduos, sendo este o momento em que o Sensemaking/Sensegiving ocorre, portanto mesmo antes de alcançar o nível de campo, ela perpassa pelas ações dos sujeitos o que seria um nível abaixo ao campo organizacional. 
FIGURA 1 - Emergência Cultural da IL a Nível de Campo

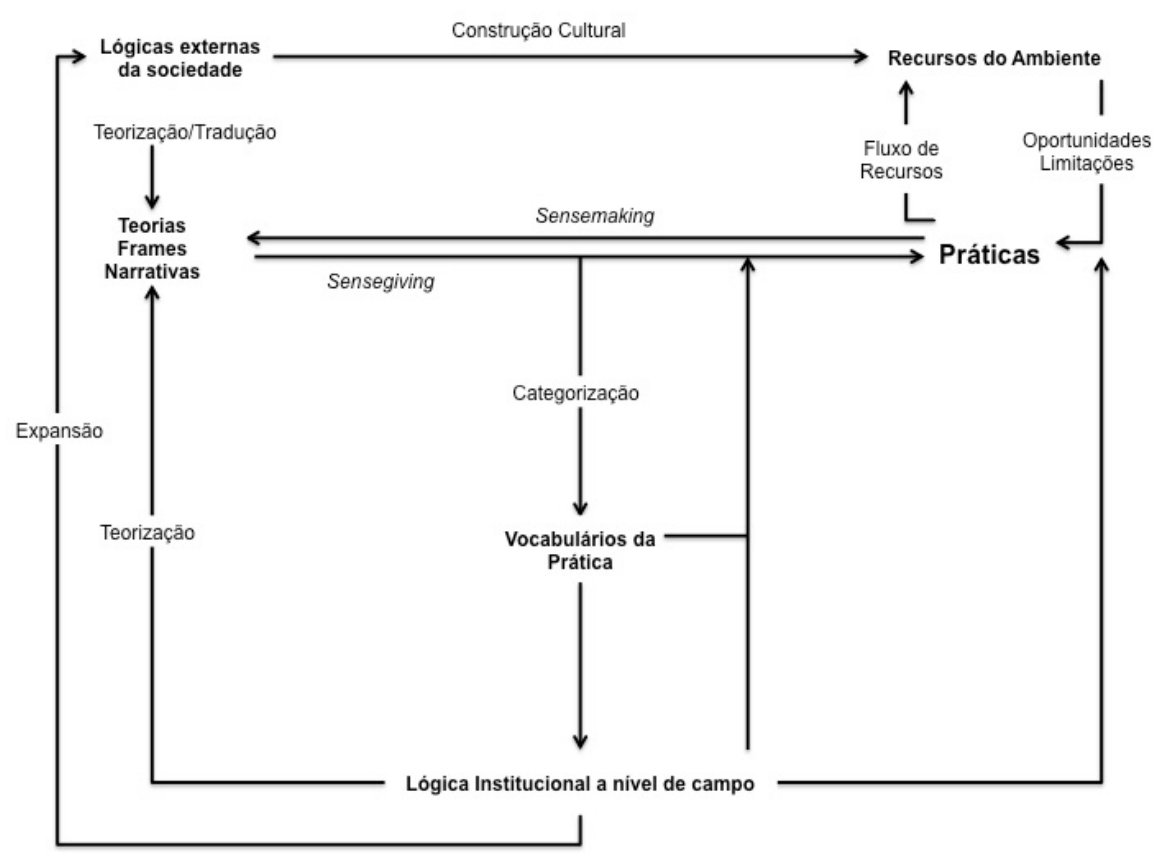

FONTE: Thornton, Ocasio e Lounsbury (2012, p. 151, tradução nossa).

Neste quadro é possível compreender a forma de como a Lógica Institucional emerge a nível de campo. Vale a pena notar que apesar dela advir de um nível societal, para alcançar o nível de campo é necessário que ela passe pelas práticas adotadas pelos indivíduos, sendo este o momento em que o Sensemaking/Sensegiving ocorre, portanto mesmo antes de alcançar o nível de campo, ela perpassa pelas ações dos sujeitos o que seria um nível abaixo ao campo organizacional.

Isto também indica que o Sensemaking, aqui compreendido como "o contínuo desenvolvimento retrospectivo de imagens plausíveis que racionalizam o que as pessoas estão fazendo (WEICK; SUTCLIFFE; OBSTFELD, 2005, p. 409, tradução nossa), aparenta ocorrer somente neste momento, pois não haveria nexo tal processo acontecer novamente uma vez que o indivíduo realiza o Sensemaking somente naquele momento em que se encontra imerso nas suas atividades (WEICK, 1995).

A fim de prover melhor suporte para compreender a figura 01, os conceitos de Giddens (2003) acerca das práticas sociais aparentam estar conectados com a Lógica Institucional, uma vez que a dualidade da estrutura em que o sujeito (indivíduo) e o objeto social (estrutura) se correlacionam entre si (GIDDENS, 2003) apresentam uma semelhança com a visão proposta pelas Lógicas Institucionais, pois ela se encontra na raiz da constituição tanto da ação quanto da estrutura, portanto a forma como o nível societal alcança o nível individual pode ter a sua visão facilitada com o apoio da teoria Giddensiana.

Apesar de Giddens (2003) não deixar claro o conceito de práticas, Nicolini (2012) aponta que as práticas podem ser compreendidas “... 
como tipos regularizados de atividades que possuem três características principais" (NICOLINI, 2012, p. 46, tradução nossa): A produção, pois as práticas são realizadas por atores com capacidade cognoscitiva; a questão temporal, espacial e paradigmaticamente situadas, e as interdependência que elas apresentam.

Esta visão acerca das práticas facilita na compreensão acerca das Lógicas Institucionais, pois a teoria proposta por Giddens (2003) apresenta um arcabouço teórico que nos auxilia a definir o que estamos olhando, pois caso contrário poderíamos prejudicar a pesquisa por estarmos observando algo que não se enquadraria como uma prática social.

Ainda na análise da figura o1 é possível perceber que as teorias/ narrativas/frames podem atuar como orientadores do Sensemaking, ou seja, atuam como Sensegivers (GIOIA; CHITTIPEDDI, 1991). No caso das organizações, isso pode ser melhor visualizado pelos documentos formais que são emitidos pelo alto escalão das organizações que visam manter as práticas sendo adotadas naquilo que eles compreendem como adequadas para a organização. No caso da Polícia Militar do Paraná, tal tentativa de orientação do Sensemaking se encontra cristalizada nas diretrizes que são emanadas pelo Comando-Geral da Corporação.

A identidade não se apresenta da figura, pois de acordo com Thornton, Ocasio e Lounsbury (2012) ela pode surgir como um resultado deste processo. Além disso, os próprios autores não indiciam como isso ocorre. Mas, para isso é possível também obter o apoio de outra teoria que apresenta congruência com os estudos das Lógicas Institucionais: o Identity Work que pode ser conceitualizado como:

os processos mutuamente constitutivos em que pessoas se esforçam para modelar uma relativa coerência e noção distintiva de auto-identidade pessoal e lutam para chegar a um acordo com e, dentro dos limites, para influenciar as várias identidades sociais que pertencem a ele nos vários millieux nos quais eles vivem as suas vidas (WATSON, 2008, p. 129, tradução nossa).

Identity Work, termo este que preferimos manter na sua versão original, refere-se ao trabalho que a identidade realiza para poder adequar a auto-identidade que o indivíduo possui à identidade social que ele apresenta (BEECH, 2008). Este conceito se encaixa naquilo que foi proposto para este artigo, pois o indivíduo é influenciado por diversas Lógicas Institucionais e dependendo do espaço em que ele se encontra pode se deparar com uma Lógica dominante diferente do espaço anterior que se encontrava (BESHAROv; SMITH, 2014), portanto neste novo ambiente a sua identidade social pode exigir uma mudança, o que poderá, por consequência, demandar o trabalho da identidade, o que aparenta ocorrer na PMPR, principalmente no momento em que ele adentra à Organização e abandona uma Lógica dominada por uma Ordem Familiar, em troca de uma fortemente orientada por uma Ordem Corporativa. 
Além disso tudo, também é preciso conceber que a Polícia Militar do Paraná também pode ser considerada uma organização Híbrida (BATTILANA; DORADO, 2010), uma vez que conforme pode ser visualizado em seu próprio nome, ela apresenta uma Lógica Militar, advinda do Exército, uma vez que conforme preconiza a Lei ela é a ele subordinada (BRASIL, 1988), e também por uma Lógica Policial que orienta a sua atividade-fim, ou seja, a execução do serviço de segurança pública (BRASIL, 1988), dentre outras lógicas.

Contudo, em organizações híbridas existem mecanismos que visam orientar o comportamento dos indivíduos, uma vez que em determinados momentos podem ser exigidos elementos de uma Lógica Institucional, e em determinados momentos aqueles provenientes da outra, assim, Battilana e Dorado (2010) apontam que estas organizações precisam desenvolver uma identidade organizacional para alcançar o equilíbrio entre tais lógicas.

Portanto, a utilização do conceito de Lógicas Institucionais a partir de uma visão macro de que a sociedade é composta por Ordens Institucionais (FRIEDELITA; ALFORD, 1991) as quais influenciam o comportamento dos indivíduos, representado por suas práticas (GIDDENS, 2003), pelo Sensemaking (WEICK, 1995) e pela identidade que pode ser construída por meio das relações sociais que são estabelecidas (WATsON, 2008), pode auxiliar a compreender como as organizações, em especial no caso da Polícia Militar do Paraná, atuam como intermediadoras de tal influência, podendo até mesmo atuar como Sensegiver (GIOIA; CHITTIPEDDI, 1991).

\section{O CASO}

Este artigo trata de um Estudo de Caso realizado na Polícia Militar, uma vez que o seu processo especial de formação do indivíduo que ingressa nos quadros da Corporação representa um caso excepcional no meio organizacional (YIN, 2005) uma vez que na maioria das organizações os sujeitos que pretendem prestar serviços se encontram formados por outras organizações, ou adquirem treinamentos de curto prazo para se adaptarem à nova realidade, e no caso da PMPR, o curso é intensivo e busca fomentar neste indivíduo uma identidade: o policial militar (PONCIONI, 2005).

O Curso de Formação de Oficiais representa de forma clara este processo. Após ser submetido a um exame de seleção que se compões de provas psicotécnicas, físicas, e de saúde, o candidato precisa ser aprovado no vestibular da Universidade Federal do Paraná, conforme Edital do Concurso (UFPR, 2015). Após isso, o novo policial militar, aqui denominado por Cadete, é encaminhado para a Academia Policial Militar do Guatupê em que enfrentará um curso de 03 anos na Escola de Formação de Oficiais ( $\mathrm{EsO})$ o qual poderá ocorrer em regime de internato (o aluno somente pode sair da Academia nos finais de semana), tendo aulas no período matutino e vespertino, além de extensas atividades extra-curriculares. 
O conteúdo das disciplinas apresenta um cunho voltado para a atividade policial, mas as práticas militares são constantemente vivenciadas pelos alunos, que precisam cumprir os rígidos horários das atividades que variam desde o horário de acordar e tomar café da manhã, até mesmo os horários das revistas e inspeções.

Após os três anos de curso, é esperado que o Aspirante-a-Oficial (nome dado ao cadete formado) seja capaz de atuar no meio policial, comandando frações de tropa, e de acordo com a evolução da carreira policial, ele pode alcançar o posto de Coronel de Polícia em que desempenhará funções estratégicas de governabilidade da Corporação.

\section{METODOLOGIA}

Assim, para esta pesquisa foi adotado proposto por Stake (2009) em que foram estabelecidas as questões de pesquisa (Questões Éticas) que orientaram toda a coleta de dados, e durante as análises foram respondidas as questões imanentes, ou seja, aquelas que surgem dos dados e que precisam ser respondidas tendo por base a teoria, o que por consequência serve de argumento para responder às questões émicas (STAKE, 2009).

Assim, foram estabelecidas as seguintes questões éticas:

Como a Lógica Institucional orienta o processo de socialização, formação e ação dos indivíduos que aceitam se submeter aos preceitos da Polícia Militar do Paraná?

Como a organização molda a identidade dos indivíduos, e as práticas por ele adotadas, que já passaram pelo processo de formação?

Como os indivíduos lidam com as Lógicas Institucionais conflitantes, seja no processo de formação, seja na ação em si?

Assim, espera-se que ao final do estudo a resposta para estas perguntas auxilie a encontrar a resposta para a questão que orienta esta pesquisa: como as lógicas institucionais atuam como orientadoras das práticas adotadas pelos indivíduos, intermediada pelas organizações que eles se encontram imersos.

Para tanto, foram realizadas 30 entrevistas narrativas com indivíduos que compõem a Corporação atualmente, divididos da seguinte forma:

12 cadetes foram entrevistados no primeiro dia em que se apresentaram na academia;

12 cadetes e mais o1 foram entrevistados 60 dias depois de terem adentrado à academia;

O1 entrevista com o Comandante da Escola de Oficiais a fim de compreender como era a rotina da EsO na época da entrevista; 
o3 entrevistas com os Aspirantes-a-Oficial que se formaram recentemente na Escola;

o1 entrevista com um capitão que se encontrava atuante na Corporação.

Todas as entrevistas seguiram o protocolo indicado por Jovchelovitch e Bauer (2015) em que a primeira parte da entrevista visava apresentar a pesquisa e o objetivo da entrevista, e se autorizava a gravação da mesma, sendo que todas foram devidamente gravadas e transcritas. A segunda fase visava a coleta da narração central em que o entrevistado somente respondia a determinadas questões que visavam limitar a história que ele narrava, como por exemplo: como foram os sessenta dias de escola? A terceira fase era representada pelas perguntas realizadas pelo pesquisador que buscava esclarecer somente alguns pontos que haviam ficado escurecidos durante a narrativa. Já a quarta fase, com o gravador desligado, o entrevistador buscou estabelecer uma conversa mais próxima do entrevistado a fim de coletar outros detalhes que poderiam ter sido passado despercebidos, e talvez influenciados pela presença do gravador. Por fim, a última fase era representada pela anotação na folha da entrevista das observações que foram identificadas na entrevista: impressões sobre o entrevistado (nervosismo, estresse, emoções, etc) ou sobre como a entrevista tinha ocorrido.

Após a coleta, todas as entrevistas foram transcritas e analisadas de acordo com o que prescreve Riessman (2008), em que ela aponta que:

No estudo das narrativas, entretanto, a atenção muda para os detalhes - como e por que um evento em particular é relatado, talvez, ou o que o narrador compreende ao desenvolver a história daquele jeito, bem como os efeitos no leitor ou no ouvinte (RIESSMAN, 2008, p. 12, tradução nossa)

Portanto, o foco é na história e em suas contraposições e fatos apresentados. Tal mudança é necessária uma vez que Jovchelovitch e Bauer (2015) apresentam a análise de conteúdo como ferramenta mais indicada, mas para esta pesquisa, isto aparenta não apresentar o resultado que esperamos coletar.

Assim, as entrevistas foram analisadas em suas partes, tendo por foco a experiência a que os entrevistados foram submetidos, bem como a forma com que eles deram sentido à tudo aquilo (WEICK, 1995), e também como a organização pode ter agido orientado a formação deste sentido (GIOIA; CHITTIPEDDI, 1991).

Antes de concluir este capítulo, após a entrevista com o Comando da $\mathrm{EsO}$, também foi realizada uma análise de um vídeo em que uma reportagem ocorrida em meados do ano 2005 demonstrava como era a rotina da EsO, em que foi possível confirmar que a rotina da EsO aparenta ser a mesma ao longo dos anos, o que indica que os Oficiais que foram formados pela Academia, foram submetidos a elementos muito 
parecidos durante o período de formação. Isso é importante porque permite afirmar que todos os entrevistados passaram pelo mesmo processo, o que também permite construir uma narrativa simbólica de um indivíduo genérico que aqui será denominado de Steve. Este nome foi escolhido porque é um apelido comum entre os policiais.

Para a descrição do vídeo foi adotado o proposto por Bauer (2015). No primeira dimensão temos a descrição daquilo que pode ser visto no vídeo, e na segunda dimensão podemos verificar aquilo que a repórter está relatando durante a reportagem.

Já a análise do vídeo, foi adotada a abdução como ferramenta de análise dos dados, uma vez que Bauer (2015) também apresenta uma análise de conteúdo dos dados descritos, o que aparenta não se encaixar no foco deste artigo.

Nós escolhemos a abdução sobre outros métodos (como o discurso e a análise de conversação) porque ela abrange a concretização como integral da experiência vivida e "método" e vai além de uma linguística pura ou análise da ação que nos permite explicar os nossos dados pela combinação e elaboração de conceitos existentes com observações que geram insights teóricos e práticos muito úteis. Estes insights emergem nem da teoria testada (dedução), nem dos dados (indução), mas de usar a teoria com os dados de maneiras criativas. (CUNLIFFE; CUPLAND, 2011, p. 71, tradução nossa)

Assim, por meio da conjunção da entrevista narrativa realizada com o Comando da Escola de Oficiais, e da análise do vídeo, foi possível elaborar questões que serviram de base para orientar a coleta da entrevista da narrativa com os Aspirantes-a-Oficial, e também com o capitão.

Ao final desta análise, foi elaborada uma história que contém todos os elementos que foram coletados, a qual será apresentada neste artigo. A narrativa de Steve visa conter todos estes elementos, e espera-se que todos os policiais que lerem tal narrativa, consigam identificar-se a rotina de suas carreiras com algumas de suas partes ali relatadas.

\section{COLETA DE DADOS}

As primeiras entrevistas que foram coletados foram aquelas realizadas com os cadetes do primeiro ano do Curso de Formação de Oficiais (CFO) no primeiro dia que se apresentaram na Academia Policial Militar do Guatupê. Para ser entrevistado, o cadete não podia ter sido policial militar, nem ter sido reprovado no curso, pois esta primeira fase da entrevista visava coletar como eram as práticas adotadas pelos sujeitos antes de entrar na academia, e durante o processo de seleção, ou seja, foi uma tentativa de escolher aqueles que não tinham sofrido influência das Lógicas Institucionais (IL) da PMPR. Além disso, esta entrevista visava também coletar como era a identidade apresentada pelo sujeito antes de entrar na academia, para na segunda rodada de 
entrevistas tentar identificar como o Identity Work (wATSON, 2008) tinha sido realizado, se é que ele tinha ocorrido.

A entrevista foi coletada em um momento que se aparentava com um turbilhão de informações, este pesquisador teve a impressão de que os novos cadetes estavam preocupados com suas posturas, e que estava muito cansados devido às exaustivas atividades que tinham realizado naquela data. Contudo, todos apresentavam uma alegria de estar ali cumprindo um sonho, pois o processo de seleção tinha sido concorrido, e a espera para a convocação tinha sido longa (cerca de seis meses).

O local da entrevista teve que ser adaptado, pois enquanto um cadete era entrevistado, os demais eram ensinados e cobrados pelos cadetes veteranos do terceiro ano do CFO, entretanto que de início aparentava se tratar de uma perturbação à entrevista, tornou-se um fator que fez perceber como a rotina dos cadetes era intensa e fez relembrar algumas coisas que este entrevistador passou durante o período de formação para Oficial.

Já a segunda rodada de entrevistas ocorreu exatos 60 dias depois da primeira, em que já era possível perceber uma mudança física nos cadetes, pois estavam mais magros, e também parecia que a entrevista estava ocupando os seus curtos e precioso tempos. Na segunda entrevista foi possível identificar que o Identity Work tinha ocorrido devido à mudança do ambiente e que os próprios entrevistados não percebiam isso, tanto é que alguns deles ou percebiam a mudança dos atributos da identidade somente quando os seus familiares comentavam com eles, ou quando lhes foi perguntado se eles percebiam se algo tinha mudado durante aquele período.

Após as entrevistas com os cadetes, foi realizada a entrevista com o comandante da Escola que durou mais de 40 minutos de entrevista gravada, e mais cerca de uma hora de conversa após a gravação. Esta entrevista foi realizada em um ambiente tranquilo, e o entrevistado estava bastante disposto a participar e a colaborar com os dados em que foi possível compreender de uma forma ampla como era a rotina dos cadetes na Escola de Oficiais, a qual foi confrontada com o vídeo e identificado que a rotina apresenta os mesmos contornos tanto no vídeo, como no relato realizado pelo Comandante.

Já a entrevista com os três Aspirantes-a-Oficial, teve um fator complicador que foi o local da entrevista. Estes policiais se encontram submetidos a estágio, e portanto apresentam uma alta carga de atividades, sendo que o primeiro foi entrevistado no momento que saía da cidade de Curitiba para trabalhar em outra cidade que se encontrava classificado, o segundo teve que acontecer na sede da unidade que se encontrava escalado, mas com o celular ligado para qualquer eventualidade, o que ocorreu no meio da entrevista, e o terceiro foi entrevistado dentro da viatura policial, enquanto ele se encontrava de serviço, pois na sede da unidade não havia espaço disponível para a entrevista. A impressão desta entrevista é que os Aspirantes realizam uma forma- 
ção básica na Academia, mas quando se deparam com a atividade-fim da Corporação, enfrentam uma rotina diferente daquilo que lhes foi ensinado, e eles afirmaram que muita coisa era aprendida com os seus subordinados, durante as atividades policiais que desempenhavam rotineiramente.

Por fim, a entrevista que foi realizada com o capitão também teve que ser realizada no local em que ele se encontrava classificado devido à alta carga de trabalho, e durou aproximadamente uma hora. Este pesquisador tentou entrevistar outros dois oficiais, mas eles se encontravam demasiadamente ocupados, e as agendas estavam cheias, o que impediu a realização da entrevista. Entretanto, foi possível perceber que o processo de socialização (LOUIS, 1980; vAN MAANEN, 1977) é semelhante ao que os cadetes entrevistados foram submetidos, e também semelhante àquele experienciado pelos Aspirantes.

\section{A NARRATIVA DE STEVE}

“Tinha dezesseis anos. Estava em casa eu, minha mãe e meu pai... e meu irmão também, no quarto, como sempre... Morávamos em uma casa no Portão, mas depois do que aconteceu nos mudamos para um apartamento. Naquele dia, ouvimos um barulho no portão e eu fui ver o que era, achei que era o Marlon, meu vizinho, mas vi que eram dois rapazes morenos, e um deles gritou pra mim que era um assalto enquanto o outro arrombou a porta e mandou eu deitar no chão. Eu fiquei sem reação porque nunca tinha passado por um assalto antes, a gente sempre ouve isso acontecer na televisão, mas nunca imagina que isso vai acontecer com a gente. Ficamos todos deitados no chão da sala enquanto eu ouvia que eles estavam mexendo nas coisas, pediam dinheiro, e chegaram a bater no meu pai. Eu tinha dezesseis anos naquela época, mas fiquei com muita raiva daquilo. Pô! Não precisava bater, era só levar tudo embora, a gente estava no chão, de boa, afinal de contas eles estavam com uma arma de fogo preta na mão, que hoje, eu sei que era uma pistola.

De repente a gente ouviu um barulho no portão, eram dois policiais que tinham chegado, os dois ladrões ficaram desesperados e estavam correndo para os fundos da casa, quando os policiais entraram pela porta da frente, e meu irmão, mais velho que eu, falou para eles que os ladrões tinham corrido para o fundo. Minha mãe, coitada, chorava muito, e eu estava em estado de choque com tudo que estava acontecendo, e pensar que alguns momentos antes estava tudo tranquilo e agora tinha toda aquela correria à nossa volta.

Os policiais militares, fardados, foram muito rápidos, pegaram a informação de meu irmão e foram correr atrás dos malas, e conseguiram pegar. Meu pai teve que ir até a delegacia para reconhece-los, ficou com bastante medo porque tinha medo pela nossa família, vai que um dos ladrões voltasse para meter medo na gente, ou pra se vingar, sei lá.

Eu nunca mais vi aqueles caras, nunca tinha visto eles na vila, mas depois daquela data tivemos que nos mudar pra um apartamento, 
minha mãe que sempre morou ali teve que se mudar porque não conseguia mais dormir direito, aquilo me marcou muito, coitada. Apesar desse momento de sofrimento, a partir daquele momento eu comecei a procurar informações sobre o trabalho que a PM faz, e desde então, eu não sei por que, comecei a me interessar por aquilo e decidi que iria ser policial para defender aqueles que precisavam de ajuda, e evitar que pessoas como a minha mãe sofressem. De certa forma, o que eu sou hoje é graças àquele ladrão.

Em minhas pesquisas sobre a PM eu vi muita coisa legal, muita coisa fascinante, mas também ouvi algumas histórias que me chamaram a atenção, castigos físicos, coisas que ocorreram no período de formação, mas aquilo me chamou mais o interesse do que me afastar daquilo, eu que sonhava em ser médico, trabalhar em um consultório, estava ali me imaginando correndo atrás de ladrões, fazendo as coisas que a gente vê nos filmes, ledo engano (risos).

Procurei mais informações e descobri que tinha duas formas de entrar na PM a primeira pelo concurso da PM para ser soldado e outra para ser Oficial, pelo vestibular da federal, naquele momento eu não entendia exatamente a diferença, mas escolhi tentar o CFO pela diferença salarial que me pareceu grande.

Desde então eu tive que adaptar toda a minha rotina, imagina, eu que ficava em casa o dia inteiro, minha mãe fazia comida, meu pai me dava dinheiro, a minha incomodação era meu irmão, e tinha só que cuidar de não perder o horário da escola, e de uma hora pra outra me enfiei de cabeça nos livros, porque eu tinha decidido fazer o CFO em maio, e a prova era em novembro, portanto eu tinha pouco tempo. Meus pais não queriam que eu fizesse, a princípio, ainda estavam muito abalados pelo que tínhamos passado, mas com o passar do tempo eles perceberam a minha vontade e conseguiram até pagar um cursinho pra mim. A minha rotina mudou, era casa, cursinho, casa, meus amigos reclamaram um monte, começaram a me chamar de CDF, perdi muitos deles naquela época, e os outros eu perdi durante o CFO, mas a vida é feita disso, escolhas, e eu fiz a minha e me dediquei a ela.

O vestibular da federal foi difícil, mas eu consegui ser aprovado, sensação incrível! Foi concorrido, 80 por vaga, mas eu passei, peguei a minha vaga! Mas, o mais difícil ainda estava por vir, as provas específicas; a mais difícil foi a avaliação física, a barra era muito difícil pra mim, imagina, eu nunca tinha feito atividade física nenhuma e de repente eu tinha que fazer 1o barras, mas aos poucos eu fui treinando e consegui fazer aquilo.

Quando tive o resultado final, foi uma sensação incrível, eu estava prestes a entrar naquilo que eu tinha sonhado ao longo daquele ano, às vezes eu penso que um ano atrás daquilo eu estava me preparando para fazer medicina, e no ano seguinte estava lá me ferrando na academia.

Foi um período de ansiedade, ter que esperar pra ser chamado pro concurso, e quando fomos convocados foi muito legal, ao mesmo 
tempo me lembrava das histórias estranhas que ocorriam na academia, mas também tinha aquela expectativa para aquele futuro que estava por vir. Nos apresentamos no QCG e eu nunca tinha visto nenhum deles que estavam ali, muito estranhos, mas começamos a conversar e vimos que tínhamos quase abandonado tudo para estar ali, muitos já tinham tentado por várias vezes, outros que nem eu, era a primeira, e outros que não tinha me dado bem por achar que era muito orgulhoso, pois alegava que já era militar e que sabia de tudo.

O comandante da EsO nos recebeu e explicou como seria a nossa rotina, a partir dali eu percebi que teríamos muita coisa pra fazer, e eu não tinha ideia de como iria fazer tudo aquilo, mas fomos dispensados para preparar o nosso enxoval e ajustar algumas documentações pendentes, pois a partir do dia seguinte entraríamos em quarentena. A tão temida quarentena que eu sempre ouvia falar.

Cheguei em casa, minha mãe me abraçou e pediu para eu não ir, falou que me ajudava a procurar emprego, e que daria um jeito até para pagar a faculdade de medicina, hoje eu vejo que talvez devesse ter aceito, não sei. Hoje eu estou bem, tenho família e tal, uma vida boa, mas hoje eu vejo o quanto de risco eu corri, mas apesar disso, tudo valeu muito a pena, as coisas que a PM tem me proporcionado somente um PM como eu pode compreender.

Falei pra minha mãe que era aquilo que eu queria, e que já estava decidido, ela entendeu, enxugou as lágrimas e falou que iria me apoiar para o que eu precisasse. Naquela noite, eu precisava era de sono, precisava dormir, mas estava ansioso demais para ir para a academia... Ah! Se eu soubesse! Teria dormido feito um bebê!

Nos apresentamos na academia na segunda-feira cedo, entrar na APMG foi muito legal, eu estava muito empolgado, com uma energia para fazer tanta coisa. A primeira semana foi bastante interessante, senti muita falta daquela noite antes de vir pra APMG, pois não dormimos nada, passaram pra gente a nossa rotina, e como esperava que deveríamos nos comportar, limpar o quarto toda manhã, prestar continência a todo instante para os superiores, decorar a hierarquia da PM, cumprir as ordens, administrar o tempo, atividades físicas, pagar flexão, e além disso tudo: estudar, que me pareceu ser a última coisa a se fazer num local dedicado para o estudo.

Demorei duas semanas para entender como tudo aquilo funcionava, mas depois as coisas ficaram mais tranquilas. $\mathrm{O}$ mais difícil na verdade não era a academia, porque depois que a gente entra na rotina nem percebe, aqueles três anos passaram rápido, mas naquela época contávamos os dias pra terminar. O mais difícil na verdade era quando íamos pra casa e tínhamos que voltar, no primeiro ano por diversas vezes eu pensei em ficar em casa e não voltar nunca mais para aquele local, ainda bem que minha mãe não me fez mais aquela oferta de me apoiar na medicina, senão era capaz de eu ter aceito.

Meus pais falaram que eu mudei muito antes de entrar na academia, que antes eu era mais atencioso, ficava mais junto deles, e depois 
da EsO eu fiquei mais quieto, na minha, mais frio, responsável e organizado, mas eu demorei pra perceber que aquele Steve que existia antes da EsO não existia mais.

A rotina na EsO era bem puxada, acordar cedo, limpar o quarto, cumprir ordens, estudar, cumprir as missões específicas, mas o que era legal e o que tenho até hoje são os amigos que eu fiz lá dentro, porque os amigos que eu tinha fora da $\mathrm{EsO}$ foram sumindo ao longo do tempo, deve ser porque eu não tinha outro assunto pra falar a não ser EsO, LC, limpeza de quarto e de vidro e é claro: a Polícia Militar.

O companheirismo que se estabeleceu lá dentro foi algo que eu tenho até hoje, então, lembra daquele cara que eu falei que eu achei orgulhoso, então, se tornou um dos meus melhores amigos. A amizade que foi se formando ali dentro foi ao redor do que estávamos passando, e a própria $\mathrm{EsO}$ parece encaminhar os cadetes para isso, o Espírito de Corpo que a nossa turma, e em especial o pessoal do alojamento criou, foi muito boa.

Receber a biriba e a farda foi algo que me marcou muito naquela época, todo aquele esforço, toda aquela dedicação estavam ali, naquele nome que aparecia naquela biriba, e naquela farda que eu vestia. Minha família tomou um susto quando me viram fardado pela primeira vez, chegaram até me perguntar se eu ia andar armado, nem me atrevi a responder (risos), contudo minha mãe ainda se preocupava com a minha segurança, e sempre pedia para eu andar de colete e me proteger.

A relação com as outras turmas foi tranquila, mesmo com os terceiro anistas nos cobrando e anotando o tempo todo, contudo com o passar do tempo fomos entendendo as regras do jogo, e já no segundo ano ficamos mais tranquilos, observando como os novos terceiro anistas coordenavam a escola, com o que a gente não concordava muito, mas quando assumimos o terceiro-ano conseguimos colocar as nossas ideias em prática, não todas elas porque a coordenação da EsO já tinha tudo formatado, então a gente somente tinha que cumprir com a rotina que estava programada.

O terceiro-ano foi bastante corrido, preparar os bixos para a entrega do Espadim, depois as formaturas, os treinos com a espada, as disciplinas mais voltadas para a ação policial, e por fim a entrega da Espada. Esse momento foi inesquecível para mim e para todos da minha família, aquele momento em que nunca mais precisaria me submeter àquela rotina, um momento de libertação em que eu fazia parte da PM e que iria finalmente à ação, iria agir igual aos filmes da TV, a minha vontade era trabalhar na RONE em Curitiba, foi muito massa tirar o estágio com eles no terceiro ano, mas ninguém da minha turma acompanhou nenhuma ocorrência de vulto com eles, ficamos muito bravos com isso.

Entretanto, no nosso estágio fomos encaminhados para o interior do Estado, turma pequena, 40 alunos, fomos em dois ou três para cada unidade do interior. Esse período foi difícil, pois ali eu vi que aqueles três anos de EsO só me deram uma parte do que eu precisava saber, no 
meu primeiro dia de Oficial CPU eu não sabia ao certo o que tinha que fazer, mas eu fui fazendo e fui percebendo que aquilo que eu estava fazendo estava dando certo. Os praças foram fundamentais nesse período, porque eram eles que estavam ao meu lado no dia-a-dia do serviço. Os oficiais, devido ao acúmulo de serviço que tinham, pois tinha alguns que respondiam por 3 funções na mesma unidade, tentavam me orientar, explicar como as coisas funcionavam, mas eles não poderiam ficar comigo 24 horas por dia, na madrugada, nas ocorrências era eu e os praças, e hoje eu digo, na academia eu aprendi a teoria, mas a prática eu aprendi com os praças, em especial com um sargento antigão que se tornou mais que um colega de trabalho. O espírito de corpo da academia se refletiu na atividade operacional, em grande parte dos policiais, pois tinham muitos que não se preocupavam com o serviço.

A escala de serviço de Oficial CPU era cansativa, não dava tempo de fazer nada, e quando tínhamos folga aparecia uma escala extra ou então tínhamos os procedimentos administrativos para realizar: apurar transgressões disciplinares, acidentes de viaturas, etc, era muito papel e, fazer isso a academia não ensinou muito bem.

Ao longo da carreira fui percebendo que algumas coisas eram feitas de forma diferente daquilo que a academia ensinava, e o resultado que elas apresentavam era o mesmo e sem precisar fazer muito trabalho.

No período em que fui tenente as responsabilidades foram aumentado ao longo do tempo, e pude perceber que o trabalho operacional era mais exaltado do que o trabalho administrativo. Eu sempre tentei me manter no trabalho operacional, e quando voltei para Curitiba tentei trabalhar na RONE novamente, e consegui lá permanecer por um determinado período, era muito legal acompanhar as principais ocorrências, a união dos policiais para cumprir um objetivo era muito alta, e a gente sempre trabalhava integrado, aprendi muito trabalhando lá, e também fiz muita coisa de que me arrependo, principalmente não dar atenção devida para alguns problemas que os policiais apresentavam, em especial aqueles que envolviam a relação deles com a família.

Neste período acabei me casando e tendo dois filhos, e por causa do serviço na RONE quase perdi a minha família. Este tipo de serviço demanda demais a dedicação dos policiais, em uma escala fixa, que parecia que eu tinha retornado para a época de estágio de Aspirante.

Depois deste período, mudei de atividade para o administrativo em que as coisas pareciam ocorrer de um modo muito diferente daquilo que eu realizava na RONE, mas eu pude compreender de uma forma melhor como as coisas acontecem na PM, e como é difícil dar suporte para os policiais que estão realizando a atividade-fim.

Recentemente, fui promovido a capitão, e retornei para a atividade operacional, mas comandando uma companhia de uma unidade operacional da capital, o que tem sido um novo aprendizado para mim, pois nunca tinha exercido essa função antes. Lá eu tive que aprender a como lidar com todos os policiais e os seus mais complexos problemas, 
pois na RONE os policiais eram selecionados, apresentavam problemas, mas eram escolhidos para estarem ali, já na companhia eu não tinha essa possibilidade, eu tinha que trabalhar com o que eu tinha em mãos, e o mais difícil foi aprender como comandar esse grupo de policiais, em especial a gestão do recurso humano é bastante complicada, mas fui observando como os outros agiam, em especial os praças antigos, e alguns oficiais mais modernos, conversei com colegas de turma, e fui desenrolando no serviço, administrando da melhor forma possível baseado naquilo que tinha observado ao longo da minha experiência profissional, mas ninguém tinha me ensinado sobre o que deveria fazer, eu me guiava por aquilo que eu acreditava estar fazendo certo e pelo que meu comandante orientava por ser o certo a fazer.

Hoje, quando eu olho para o passado percebo o quanto eu tive que mudar para estar aqui hoje, antes de entrar na PM eu esperava fazer uma coisa, e agora que estou aqui, capitão de polícia, estou fazendo outra atividade. Esperava estar no operacional, mas hoje estou no administrativo, não que isso seja ruim, mas a Corporação me encaminhou para isso, os valores que fui construindo, a minha imagem que foi se sedimentando ao longo do tempo, tudo isso foi a PM quem me encaminhou.

Hoje, olhando para trás, eu não me arrependo de nada do que fiz, valeu muito a pena eu ter passado por todo esse processo de ter trabalhado um período no interior, voltado pra Curitiba, que é outra realidade, trabalhado em uma unidade especializada, ter trabalhado com a ponta da nossa atividade-fim e agora no administrativo, é um desafio que nos é proposto todo dia, mas somos militares e estamos prontos para tudo, isso é o modo como eu encaro as coisas."

\section{ANÁLISE DOS RESULTADOS}

Para este tópico serão respondidas as perguntas éticas (STAKE, 2009) que foram apresentadas durante a exposição da metodologia, a primeira questão: Como a Lógica Institucional orienta o processo de socialização, formação e ação dos indivíduos que aceitam se submeter aos preceitos da Polícia Militar do Paraná?

Esta questão pode ser respondida por meio da análise do primeiro período de formação do Oficial, ou seja, por meio das entrevistas que foram realizadas no momento da entrada do sujeito na Academia, bem aquelas que foram realizadas sessenta dias depois.

A primeira questão émica (STAKE, 2009) que surge refere-se à questão da identidade, pois é preciso compreender se houve alguma mudança na identidade do indivíduo, ou não. Watson (2008) afirma que para o Identity Work ocorrer é necessário que haja algum tipo de mudança externa, seja no ambiente, seja nas relações estabelecidas, portanto era de se esperar que os indivíduos tivessem as suas auto-identidades alteradas, o que de fato ocorreu, pois durante as entrevistas foi identificado que antes de entrar na $\mathrm{EsO}$, alguns entrevistados apresentavam comportamento preguiçoso, relapso, principalmente orientado pela 
rotina casa-escola, e que após entrar na EsO isso se alterou para um comportamento responsável, quieto, sério, os quais podem representar atributos da identidade (LOK, 2010) que indicam que houve mudança na sua identidade, o que também aconteceu com nosso Steve:

Meus pais falaram que eu mudei muito antes de entrar na academia, que antes eu era mais atencioso, ficava mais junto deles, e depois da EsO eu fiquei mais quieto, na minha, mais frio, responsável e organizado, mas eu demorei pra perceber que aquele Steve que existia antes da EsO não existia mais. (STEVE, 2015)

Weick (1995) também aponta que a identidade pode ser compreendida como o resultado de um Sensemaking, assim há de se considerar que nesse momento inicial de socialização houve um intenso Sensemaking uma vez que muitos gatilhos foram identificados durante as entrevistas: aumento da emoção, mudança do ambiente, pressão para adequação das práticas (WEICK, 1995).

Mas, retornando à questão ética de como as Lógicas Institucionais podem orientar todo este processo é preciso acrescentar o Sensegiving (GIOIA; CHITTIPEDDI, 1991) como essencial para que as organizações, por meio dos indivíduos que a compõem, consigam atuar como meio de orientação.

Conforme Thornton, Ocasio, e Lounsubry (2012) afirmam, as organizações se encontram sob influência das Lógicas Institucionais advindas de um nível societal, sendo que para alcançar o nível de campo é necessário que ocorra o Sensemaking. Tendo isso em mente, é importante perceber que tal processo não ocorre novamente quando se analisa a emergência da Lógica Institucional a nível organizacional, uma vez que no nível de campo as IL influenciam todas as organizações de um modo geral.

Portanto, no caso da Polícia Militar, é possível perceber que todos os sujeitos que desempenham a função de segurança pública, seja na área da Polícia Civil, ou da Polícia Militar (PONCIONI, 2005) buscam formar indivíduos para prover segurança pública aos componentes da sociedade. Portanto, as Lógicas Institucionais que influenciam os agentes de segurança podem ser em sua grande maioria as mesmas, contudo as identidades organizacionais são diferentes.

Esta afirmação tem por base o fato de que quando as Lógicas alcançam o nível de campo, o Sensemaking já ocorreu, independente da organização que o indivíduo pertence, pois este processo ocorre somente uma vez, mas as práticas que são adotadas e os respectivos valores em cada organização são diferentes, o que leva a apresentar identidades diferentes.

Isso é perceptível porque a Academia, no período inicial de socialização busca incutir nos cadetes a importância dos valores militares, tais como a hierarquia, a disciplina, e para alcançar isto ela atua como um Sensegiver indicando qual o resultado do Sensemaking é mais ade- 
quado para as suas práticas. O indivíduo possui certa liberdade para identificar as pistas no ambiente e realizar a compreensão que lhe convém (WEICK, 1995), contudo nem toda interpretação está de acordo com aquilo que a organização define como adequado, para isso a Academia impõe horários rígidos, posturas adequadas, ações esperadas etc, e se o cadete não as realiza é sancionado. Portanto, o resultado de seu Sensemaking tem que se enquadrar naquilo que é pré-determinado, caso contrário será punido.

Ocorre que devido ao fato de que nenhum indivíduo é completamente livre (BERGER, 2000), e quem define "o correto" para as organizações são os próprios indivíduos que a compõem, há de se considerar que esta definição é realizada pelo Comando da Corporação, o qual por sua vez também se encontra sendo orientado pela Lógica Institucional que se encontra imerso, portanto é possível perceber a importância das IL para as organizações, pois é com o suporte delas que os indivíduos conseguem alterar suas identidades, e também escolher as práticas que sustentam a própria organização.

Para a segunda questão ética (STAKE, 2009) é preciso analisar o período pós-formação e o suporte a esta resposta vem das narrativas coletadas dos Aspirantes e do Capitão da PMPR.

Após ser formado, o cadete é formado Aspirante a Oficial e é designado para executar as funções de Comando da Corporação e no período de um ano tem que realizar um estágio probatório a fim de avaliar se o sujeito internalizou os conhecimentos aprendidos durante o período de formação. Ocorre que, conforme relatado nas narrativas, os Aspirantes se deparam com uma realidade aparentemente diferente daquela que foi ensinado, por dois motivos:

1) Porque conforme entrevista coletada com o comandante da escola, o cadete adquire uma formação fortemente baseada no conceito teórico em que se busca orientar o futuro profissional acerca daquilo que é correto, uma vez que ele será o responsável por corrigir possíveis desvios para enquadrar as práticas naquilo que a organização define como correto.

2) Porque na época da academia o cadete aparenta ser orientado por uma Lógica Policial e uma Lógica Militar, a primeira se refere aos conteúdos que são repassados para os cadetes, e a segunda são as práticas adotadas no dia-a-dia do cadete. E na época da ação, a Lógica Militar aparenta adquirir contornos de uma cultura organizacional, e a Lógica Policial aparenta se dividir em duas Lógicas complementares e aparentemente conflitantes: uma Lógica Administrativa e uma Lógica Policial, a primeira se refere às práticas administrativas de suporte à atividade-fim, e a segunda se refere às práticas do serviço de segurança pública, ou a atividade-fim em si realizada pela PMPR, portanto se depara com IL dominantes (BESHAROv; SMITH, 2014) diferentes o que pode causar conflito da ação. 
Diante destes dois motivos, surge as duas questões émicas (STAKE, 2009): como o sujeito lida com a responsabilidade de ser aquele que orienta os demais policiais militares sendo que foi formado no campo teórico da ação? Como o indivíduo lida com as mudança de Lógica por vezes conflitantes?

Para a primeira questão, é preciso observar aquilo que foi relatado pelos Aspirantes-a-Oficial acerca do estágio, que pode ser melhor resumida na fala de Steve:

Esse período foi difícil, pois ali eu vi que aqueles três anos de EsO só me deram uma parte do que eu precisava saber, no meu primeiro dia de Oficial CPU eu não sabia ao certo o que tinha que fazer, mas eu fui fazendo e fui percebendo que aquilo que eu estava fazendo estava dando certo. Os praças foram fundamentais nesse período, porque eram eles que estavam ao meu lado no dia-a-dia do serviço. Os oficiais, devido ao acúmulo de serviço que tinham, pois tinha alguns que respondiam por 3 funções na mesma unidade, tentavam me orientar, explicar como as coisas funcionavam, mas eles não poderiam ficar comigo 24 horas por dia, na madrugada, nas ocorrências era eu e os praças, e hoje eu digo, na academia eu aprendi a teoria, mas a prática eu aprendi com os praças, em especial com um sargento antigão que se tornou mais que um colega de trabalho. $\mathrm{O}$ espírito de corpo da academia se refletiu na atividade operacional, em grande parte dos policiais, pois tinham muitos que não se preocupavam com o serviço. (STEVE, 2015).

A estrutura da PMPR é fortemente hierarquizada em que o indivíduo localizado em uma posição hierarquicamente superior possui entre as várias funções, a de ser o responsável por orientar os subordinados acerca das práticas corretas que devem ser adotadas pela organização. Ocorre que o Aspirante-a-Oficial é formado para ser aquele que orienta o serviço operacional da PMPR, o Oficial Coordenador de Policiamento da Unidade (Oficial CPU), ou seja, a ele se encontram subordinados um grande grupo de policiais com bastante de experiência profissional, nominado por Steve como os "Antigões".

Ocorre que durante o processo de estágio não é possível que o Oficial hierarquicamente superior acompanhe o estagiário durante todo o momento, e por outras questões administrativas, o Aspirante acaba se tornando o orientador de atividades práticas, tendo por base somente o conhecimento teórico anteriormente aprendido.

Diante da pressão por coordenação, e da incapacidade de agir como tal, o Aspirante se vê obrigado a observar o comportamento dos subordinados e aprender com eles, no enactment contínuo das atividades, aquilo que é adotado cotidianamente, portanto é possível perceber que neste momento há uma inversão da hierarquia estabelecida, o Sensegiving que deveria partir de um nível superior, vem de um nível inferior, portanto o orientador aprende com o orientado como orientar, 
e isso aparenta ser algo aceito dentro da Corporação, porque conforme o Aspirante vai aprendendo como "as coisas funcionam" ele pode orientá-las de acordo com aquilo que foi ensinado na academia.

Portanto, o que se percebe aqui é que as IL aparentam seguir um caminho diverso daquilo que foi apresentado na resposta do item anterior, uma vez que no período de formação ela aparenta vir de um caminho superior para os subordinados, e no período da ação ele é também fortemente influenciado pelos subordinados, o que indica que nas organizações a Lógica Institucional pode influenciar o comportamento dos sujeitos que a compõem por meio das relações sociais que são estabelecidas.

Para responder a segunda questão émica (STAKE, 2009) basta analisar o período em que Steve teve que mudar de uma Lógica Operacional para uma Lógica Administrativa:

Depois deste período, mudei de atividade para o administrativo em que as coisas pareciam ocorrer de um modo muito diferente daquilo que eu realizava na RONE, mas eu pude compreender de uma forma melhor como as coisas acontecem na PM, e como é difícil dar suporte para os policiais que estão realizando a atividade-fim.

Recentemente, fui promovido a capitão, e retornei para a atividade operacional, mas comandando uma companhia de uma unidade operacional da capital, o que tem sido um novo aprendizado para mim, pois nunca tinha exercido essa função antes. Lá eu tive que aprender a como lidar com todos os policiais e os seus mais complexos problemas, pois na RONE os policiais eram selecionados, apresentavam problemas, mas eram escolhidos para estarem ali, já na companhia eu não tinha essa possibilidade, eu tinha que trabalhar com o que eu tinha em mãos, e o mais difícil foi aprender como comandar esse grupo de policiais, em especial a gestão do recurso humano é bastante complicada, mas fui observando como os outros agiam, em especial os praças antigos, e alguns oficiais mais modernos, conversei com colegas de turma, e fui desenrolando no serviço, administrando da melhor forma possível baseado naquilo que tinha observado ao longo da minha experiência profissional, mas ninguém tinha me ensinado sobre o que deveria fazer, eu me guiava por aquilo que eu acreditava estar fazendo certo e pelo que meu comandante orientava por ser o certo a fazer. (STEVE, 2015).

Apesar de apresentar semelhanças com o processo que foi adotado no período em que Steve era Aspirante, o que ocorre aqui é que na época do aspirantado o sujeito precisa aprender a lidar com a atividade da Corporação, portanto tem que aprender a trabalhar tanto com a Lógica Administrativa, quanto com a Lógica Operacional, sendo a última a mais dominante (BESHAROv; SMITH, 2014).

Contudo, neste período mais "recente", Steve se encontrava imerso em uma Lógica Operacional, representada pela atividade de rua, 
prisão de marginais, combate ao crime, e é transferido para uma atividade dominada pela Lógica Administrativa em que a rotina, o serviço de escritório, planejamento e controle se encontram como norteadores das práticas organizacionais. Van Maanem (2009) também identificou esta dicotomia no serviço policial realizado nos Estados Unidos.

Mas, o que ocorre é que as duas lógicas (Administrativa e Operacional) aparentam serem complementares, uma vez que a atividade-fim somente pode ser realizada com o suporte da atividade-meio, e também são conflitantes, uma vez que ao policial militar aparenta que ou ele cumpre as práticas emanadas de uma Lógica ou de outra. E é neste momento que podemos visualizar a Hibridez da Polícia Militar, e o que aparenta ocorrer é que ao classificar o sujeito em determinada função o indivíduo é orientado pela organização sob qual lógica seguir, e que quanto mais ele sobe na cadeia hierárquica, mais ele tem que aprender a administrar ambas, mesmo que ele não execute as práticas em específico de cada uma delas.

Assim, já é possível responder à nossa última questão ética (STAKE, 2009), que busca analisar como os sujeitos lidam com estas Lógicas conflitantes já que a Polícia Militar se apresenta como uma organização híbrida (BATTILANA; DORADO, 2010).

O que foi possível identificar é que durante o enactment contínuo das atividades o indivíduo se depara com as práticas adotadas em cada uma das Lógicas conflitantes e por mais que a Academia procure repassar ao indivíduo qual o comportamento adequado a ser adotado, não é possível prever todas as pressões que serão sobre eles realizadas, assim o sujeito adota as suas ações de acordo com o Sensemaking que ele realiza o qual já é fortemente orientado pelas Lógicas Institucionais.

O que aparenta ocorrer também é que a base teórica que a academia fornece serve como elemento fundamental para orientar qual o resultado do Sensemaking que deve ser adotado por aquele indivíduo. Portanto, por mais que o policial não esteja sentado nos bancos escolares aprendendo, ele continua a ser orientado por aquilo que foi ensinado na academia, portanto o Sensegiving realizado pela Academia, incorporado pelos conteúdos repassados e práticas vivenciadas, aparenta ser o responsável por manter as práticas organizacionais dentro daquilo que a organização define como correto, e também permite ao indivíduo navegar nas diferentes IL que podem se apresentar (JAY, 2013).

\section{CONSIDERAÇÕES FINAIS}

A Polícia Militar do Paraná se apresenta como uma organização híbrida desde o período em que o sujeito é formado na academia até a execução das atividades policiais em si, contudo é possível perceber que ao longo da carreira policial os indivíduos precisam aprender a identificar os elementos que compõem determinadas Lógicas, bem como a aplica-los da forma correta para a organização.

A IL da PM aparenta ser orientadas pelas Ordens Estado, Profissão e Corporação mencionados por Thornton, Ocasio e Lounsbury (2012), 
o que indica que várias Lógicas se encontram influenciado a organização. Ao passar pelo filtro cultural apresentado na FIGURA 1 emergem-se as práticas e as teorias e/ou frames, os quais, intermediados por um processo de Sensemaking/Sensegiving resultam em vocabulários da prática policial e emergem a nível de campo.

O nível de campo ao qual a PMPR pertence é composto pelas mais diversas organizações policiais, polícia civil, polícia federal, bombeiros militares, os quais possuem por foco a prestação do serviço de segurança pública, e neste momento é possível afirmar que a Lógica Policial é preponderante: combate ao crime, preservação da ordem pública, etc.

Contudo, no âmbito da Polícia Militar, também existe a Lógica Militar em si, oriunda do Exército Brasileiro que define a sua estrutura e concede os valores da hierarquia e da disciplina como basilares para sua existência, estabelecendo as relações entre as IL já demonstradas neste artigo: Lógica Policial, Lógica Militar, Lógica Administrativa e Lógica Operacional.

Portanto, por estar imersa no Campo Organizacional Policial, a PMPR sofre a mesma influência que outras organizações policiais, contudo o que a torna diferente das demais é o seu caráter militar e para manter-se dentro deste diferencial ela aparenta atuar, por meio de seus indivíduos, como um Sensegiver orientando aos seus policiais qual a forma correta de agir, seja por meio dos documentos que cristalizam tais práticas, seja por meio das relações sociais que são estabelecidas.

Para pesquisas futuras, seria interessante expandir esta pesquisa para as demais Corporações do país, a fim de buscar garantir a generalização dos dados aqui encontrados, e também, ao analisar em um nível nacional, seria possível identificar quais são os elementos que compõem as IL das organizações policiais do Brasil, ou seja, expandir a pesquisa a nível de campo.

Outra pesquisa que seria interessante realizar, seria olhar para as influências políticas que permeiam a organização e como elas distorcem, ou não, a influência da IL, uma vez que algumas influências políticas podem conflitar com aquilo que a IL orienta.

Expandir esta pesquisa para outras teorias também seria interessante, principalmente para analisar como a influência das IL pode ser analisada sob o ponto de vista da Estratégia, e como isto pode ser visualizado como uma capacidade dinâmica.

Além disso, sob o ponto de vista dos preceitos da aprendizagem organizacional seria interessante analisar como a IL é sustentada pelos processos de passagem de conhecimento e aprendizagem aqui mencionados.

Assim, este artigo pretendeu demonstrar como as IL orientam as práticas adotadas pelos policiais militares, e também como a identidade policial é construída intermediada pela organização, e o foco aqui é a partir de um nível de análise organizacional, identificar como o nível individual com ele se relaciona, sem precisar analisar a fundo as questões intrínsecas que compõem o indivíduo. 


\section{REFERÊNCIAS}

BATTILANA, J.; DORADO, S. 'Building Sustainable Hybrid Organizations: the case of commercial microfinance organizations', Academy Of Management Journal. v. 53, n. 6, p. 1419-1440, 2010.

BAUER, M. W. Análise de Conteúdo Clássica: Uma revisão. In: BAUER, M. W.; GASKELL, G. (Orgss). Pesquisa Qualitativa com Texto, Imagem e Som: um manual prático. Trad.: Pedrinho A. Guareschi. 13. ed. Petrópolis, RJ: Vozes, 2015.

BEECH, N. On the Nature of Dialogic Identity Work. Organization. v. 15, n. 1, p. 51-74, 2008.

BERGER, P. L. Perspectivas Sociológicas: uma visão humanística. 21. ed., Petrópolis: Vozes, 2000.

BESHAROV, M. L.; SMITH, W. K. Multiple Institutional Logics in Organizations: explaining their varied nature and implications. Academy Management Review. v. 39, n. 3, p. 364-381, 2014.

BRASIL. Constituição (1988). Constituição da República Federativa do Brasil. Brasília, DF: Senado Federal, 1988.

FRIEDLAND, R.; ALFORD, R. Bringing Society Back In: symbols, practices and institutional contradictions. In: POWELL, W. W.; DIMAGGIO, P. J. The New Institutionalism in Organizational Analysis. Chicago: University of Chicago Press, 1991.

GIDDENS, A. A Constituição da Sociedade. Trad. Álvaro Cabral. 2. ed. São Paulo: Martins Fontes, 2003.

GIOIA, D. A.; CHITTIPEDDI, K. Sensemaking and Sensegiving in Strategic Change Initiation. Strategic Management Journal. v. 12, p. 433-448, 1991.

JOVCHELOVITCH, S.; BAUER, M. W. Entrevista Narrativa. In: BAUER, M. W.; GASKELL, G. (Orgss). Pesquisa Qualitativa com Texto, Imagem e Som: um manual prático. Trad.: Pedrinho A. Guareschi. 13. ed. Petrópolis, RJ: Vozes, 2015.

LOK, J. Institutional Logics As Identity Projects. Academy of Management Journal. v. 53, n. 6, p. 1305-1335, 2010.

LOUIS, M. R. Surprising and Sense Making: what newcomers experience in entering unfamiliar organizational settings. Administrative Science Quarterly. v. 25, p. 226-152, jun., 1980.

NICOLINI, D. Practice Theory, Work \& Organization: an introduction. Oxford: Oxford University Press, 2012.

PONCIONI, P. O Modelo Profissional Policial e a Formação Profissional do Futuro Policial nas Academias de Polícia do Estado do Rio de Janeiro. Sociedade e Estado. v. 20, n. 3, p. 585-610, set.-dez., 2005. 
RIESSMAN, C. K. Narrative Methods for the Human

Sciences. Thousand Oaks, CA: Sage, 2008.

STAKE, R. E. A Arte da Investigação com Estudos de Caso.

2. ed. Fundação Calouste Gulbenkian: Lisboa, 2009.

THORNTON, P. H.; OCASIO, W. Institutional Logics. In:

GREENWOOD, R.; OLIVER, C.; SAHLIN, K. SUDDABY, R. The Sage Handbook Of Organizational Institutionalism. London: Sage, 2008.

\section{LOUNSBURY, M. L. Institutional Logics}

Perspective: a new approach to culture, structure, and process. Oxford University Press: Oxford, 2012.

UFPR. Edital no 033/2015. Disponível em: < http://www.nc.ufpr. br/concursos_institucionais/ufpr/ps2015/documentos/cfo/ edital_33_2015.pdf>. Acesso em: 27 set. 2015, às 16:38 horas.

VAN MAANEN, J. Experiencing Organization: notes on the meaning of careers and socialization. In: VAN MAANEN, J. (Eds.) Organizational Careers: Some New Perspectives. New York: Wiley, 1977.

. Identity Work and Control in Occupational Communities. In: SITKIN, S. B.; CARDINAL, L. B.; BIJLSMAN-FRANKEMA, K. M. (Eds.). Control in Organizations: new directions in theory and research. Cambridge, UK: Cambridge University Press, 2009.

WATSON, T. J. Managing Identity: Identity Work, Personal Predicaments and Structural Circumstances.

Organization. v. 15, n. 01, p. 121-143, 2008.

WEICK, K. E. Sensemaking in Organizations: Foundations for Organizational Science. Thousand Oaks: Sage Publications, 1995.

. SUTCLIFFE, K. M.; OBSTFELD, D. Organizing and the Process of Sensemaking. Organization Science. v. 16, n. 4, p. 409-421, jul.-aug., 2005.

YIN, R. K. Estudo de Caso: planejamento e métodos. 3. ed. Porto Alegre: Bookman, 2005. 